\title{
Prevalence and factors associated with a higher risk of neck and back pain among permanent wheelchair users: a cross-sectional study
}

\author{
Francisco M. Kovacs $\mathbb{1}^{1,2} \cdot$ Jesús Seco ${ }^{2,3} \cdot$ Ana Royuela ${ }^{2,4} \cdot$ Andrés Barriga ${ }^{2,5} \cdot$ Javier Zamora ${ }^{2,6,7,8}$
}

Received: 7 August 2017 / Revised: 8 October 2017 / Accepted: 10 October 2017 / Published online: 28 December 2017

(c) International Spinal Cord Society 2018

\begin{abstract}
Study design Cross-sectional study.

Objectives To determine the prevalence of, and factors associated with, spinal pain among wheelchair users.

Setting Four Spanish hospitals specialized in providing care for wheelchair users.

Methods Persons who had used a wheelchair for a median (IRQ) of $10(5 ; 19)$ years, $27 \%$ of them due to reasons other than spinal cord injury, were recruited consecutively $(n=750)$. Data on 43 demographic, psychosocial, ergonomic, and clinical variables were collected, and analyzed. Main outcome measures were: point prevalence of neck (NP), thoracic (TP), low back pain (LBP), and pain at any spinal level (PASL); and factors associated with them.

Results Point prevalence was $56 \%$ for NP, $54 \%$ for TP, $45 \%$ for LBP, and $76 \%$ for PSAL. PASL was associated with a lower quality of life (OR $(95 \%$ CI) $0.91(0.86 ; 0.97))$. Multivariable regression models showed that the main factors associated with significant pain ( $\geq 1.5$ VAS points) were: (a) For NP: cervical spinal injury and wheelchair seat cushion thickness, (b) For TP: thoracic spinal injury and sagittal index, (c) For LBP: thoracic or lumbar spinal injury, with some sensitivity remaining, (d) For PASL: being female, living alone, and using a non-power wheelchair. Discrimination (AUC) of these models ranged between 0.638 and 0.818. p-values in the Hosmer-Lemeshow test ranged between 0.420 and 0.701. Conclusions Prevalence of spinal pain among wheelchair users is high. It is associated with a lower quality of life. Future studies should assess whether using a power wheelchair affects PASL, and if the thickness of seat cushion affects NP.

Sponsorship Spanish Back Pain Research Network
\end{abstract}

\section{Introduction}

Common low back pain (LBP) is defined as pain between the costal margins and the inferior gluteal folds, which is usually accompanied by painful limitation of movement. It may be associated with pain referred down to the leg, and is not related to fracture, direct trauma, or systemic diseases such as neoplastic, infectious, vascular, metabolic, or endocrine-related processes. Common thoracic pain (TP) is diagnosed when pain is located between the costal margins and the base of the neck, and common neck pain (NP) is

Electronic supplementary material The online version of this article (https://doi.org/10.1038/s41393-017-0029-z) contains supplementary material, which is available to authorized users.

Francisco M. Kovacs

fmkovacs@kovacs.org

Extended author information available on the last page of the article diagnosed when pain is located above that level. The latter may be accompanied by pain referred to the arm $[1,2]$.

The lifetime prevalence of common LBP among the general population is above $80 \%$. LBP is the leading cause of "years lived with disability" worldwide, while NP is the fourth $[1,2]$. Data gathered by previous studies suggest that wheelchair users also suffer from NP and LBP [3-13], and that these conditions restrict their activity, increase their time spent bedridden, and decrease quality of life $[6,7,14$ 17]. In fact, pain relief has been identified as one of the main unmet needs in the community of wheelchair users across different countries [18].

However, the prevalence of common ("mechanical") spinal pain among wheelchair users remains largely unknown; only two studies have focused on LBP and one on NP $[3,7]$. Moreover, none of these studies have included large, representative samples of wheelchair users.

The factors associated with an increased risk of NP, TP, and LBP among wheelchair users are also largely unknown. 
Wheelchair users are exposed to a number of factors, which are generally assumed to be associated with an increased risk of suffering from these conditions, such as enduring awkward positions [3, 4, 7, 8, 18-23], whole-body vibrations [24-29], and holding arms at shoulder height during extended periods of time [26, 30, 31]. Nevertheless, most studies on neck or back pain conducted with wheelchair users have focused on ergonomic factors associated with the characteristics of the wheelchair [20-31], and there is scarce evidence on whether other protective or risk factors, which are relevant among the general population, such as physical activity [32-34], play a similar role in this specific population.

Identifying the factors associated with a higher risk of NP, TP, and LBP among wheelchair users could provide a basis for further research and for designing preventive strategies which, if shown to be effective in high-quality clinical trials, may be useful for this population in practice [18].

Therefore, the objectives of this study were to: (a) Determine the prevalence of NP, TP, and LBP among wheelchair users, and (b) Identify the factors associated with a higher risk of neck or back pain among this population.

\section{Methods}

A cross-sectional study was conducted in Spain, complying all institutional and governmental regulations concerning the ethical participation of human volunteers. This study was approved by the ethical committees of the participating institutions.

\section{Participants}

Inclusion criteria were as follows: being $\geq 18$ years of age, having been a permanent user of any type of wheelchair for $\geq 1$ year, and signing the informed consent form.

Exclusion criteria were as follows: using a wheelchair intermittently or temporarily, suffering from physical or mental inability, which made it impossible to respond to the interviewer's questions (e.g., pentaplegia or senile dementia), reporting being unable to distinguish neuropathic from mechanical pain, presenting fever, and having been diagnosed (or being in the diagnostic process) of cancer, systemic infection, or any inflammatory diseases such as spondylitis or rheumatoid arthritis.

\section{Setting and procedure}

This study was conducted at four of the major Spanish hospitals offering education and training related to using a wheelchair permanently, either due to spinal cord injury or other reasons, namely Hospital Nacional de Parapléjicos de Toledo, Centro de Referencia Estatal para la Atención a Personas con Grave Discapacidad y para la Promoción de la Autonomía Personal y Atención a la Dependencia (San Andrés del Rabanedo, León), the Centro de Recuperación de Personas con Discapacidad Física (CRMF) from Salamanca, and the CRMF from Madrid.

All persons returning for follow-up consultations at the participating hospitals between November 2014 and February 2016 were screened consecutively by their treating physicians. Each participant was interviewed in person by one out of a pool of three research assistants, who assessed inclusion criteria, explained the study characteristics in detail, handed out the written informed consent, enrolled the participant, and gathered data on all the variables. In order to identify potential sources of recruitment bias, reasons for exclusion were recorded.

Although each hospital covers specific geographic areas, participants relocating from one area to another could have been recruited in different hospitals at different moments. Therefore, two research assistants at a central coordination office ensured that only one set of data per participant was included in the analysis. Data from each individual participant were introduced separately into the database by two research assistants, and cross checked for inconsistencies.

\section{Variables}

Following the study design, data were gathered on the variables that had already been linked to a higher risk of common spinal pain among the general population, and those which the authors hypothesized had the potential to increase the risk of common spinal pain specifically among wheelchair users.

Data on the following variables were gathered: age (date of birth), gender, academic level (no studies, primary school, high school, university), working (yes/no), smoking, marital status (single, married, divorced, widow/er), living alone, driving, requiring help for daily activity, type of wheelchair (manual, power, others), use of a cushion in the chair, type of cushion (silicone, foam, other), time elapsed since starting to use a wheelchair permanently (years), having presented decubitus ulcers, reason for using a wheelchair (spinal cord injury or other, e.g., degenerative neurological conditions or untreatable chronic musculoskeletal condition), level of injury, type of neurological deficit (complete, with some sensitivity remaining, with some movement remaining, with spasticity, or other), and drugs prescribed to treat pain, if any (analgesics, not opioids, opioids, non-steroidal anti-inflammatory drugs, muscle relaxants, others, e.g., gabapentine or pregabaline). 
The following variables were also recorded: height and body weight (combined in the body mass index) [35], sagittal index [36], the American Spinal Injury Association (ASIA) category ("A", or complete, with no motor or sensory function preserved; "B", sensory but not motor function is preserved below the neurological level, "C", motor function is preserved below the neurological level, and more than half of key muscles below the neurological level have a muscle grade $<3$, or "D", motor function is preserved below the neurological level, and more than half of key muscles below the neurological level have a muscle $\geq 3$ ) [37, 38], number of hours spent daily in the wheelchair [39], number of days (per week) going out of home [40], number of hours per week doing exercise and sport (and type of sport) [40], usual position while sleeping (lying on the back, stomach or side), number of hours in bed per week, mattress age, type of mattress surface (spring, latex, other viscoelastic surfaces, silicone, water, air or pressure sores, or other), mattress firmness (very soft, soft, neither soft nor firm, firm, very firm), and wheelchair seat cushion thickness $(\mathrm{cm})$.

Finally, three visual analog scales (VAS) were used to assess neck, thoracic, and LBP separately [39]. Daily activity was measured with a set of previously validated specific questions [40], while depression and quality of life were measured with the previously validated Spanish versions of the Center for Epidemiologic Studies Depression (CESD) scale [41], and the Quality Life Index/Spinal Cord Injury (QLI/SCI), respectively [42-44]. The latter has been validated for use among wheelchair users both with and without spinal cord injury [44]. Value ranges are (from best to worst) 0-10 for VAS and 0-60 for CESD (with scores $>16$ suggesting depression) [41], and, from worst to best, 0-30 for the QLI/SCI [42-44].

\section{Analysis}

At the design phase of this study, the authors listed 19 variables, which they considered had the potential to be associated with spinal pain among wheelchair users. This selection was based on clinical plausibility. Moreover, they anticipated that up to four additional variables could be significantly more frequent among participants with spinal pain. In order to assess the association between the prevalence of spinal pain and 23 potential risk factors, each of the two groups (i.e., participants with or without pain) had to include $\geq 230$ participants [45]. Therefore, assuming an error $\leq 4 \%$ and anticipating a pain prevalence of $40 \%$ and losses of $30 \%$, the sample size was established at 750 participants.

Data gathered during the study were used to estimate the point prevalence of neck, thoracic and LBP, and of pain at any of these levels, as well as the 95\% CI for each."Participants with pain" at the cervical, thoracic or lumbar levels, or at any spinal level were first defined as those with a VAS score $>0$. Previous studies have shown that the minimal clinically important change for neck and LBP is 1.5 VAS points [46, 47]. Therefore, prevalence was also calculated for "significant" pain, defined as a VAS score $>1.5$ points.

At the design phase of this study, it was anticipated that some variables could be associated with significant pain at only one spinal level (neck, thoracic, or low back), others could be associated with pain at several or all of these levels, and still others could be confounders. Therefore, four multivariable, binary, logistic regression models were developed to separately assess the factors associated with a higher prevalence of NP, TP, LBP, and pain at any spinal level. The limit for each category (significant pain vs. no significant pain) was established at 1.5 VAS points.

The variables included in the regression models were selected following clinical and statistical criteria. The variables which were selected based on clinical criteria were defined at the design phase of the study. These were: age, gender, number of hours per week doing exercise or sport, quality of life (QLI-SCI), depression (CESD score), type of wheelchair, reason for using a wheelchair, level of spinal injury, and ASIA score. In the model on pain at one spinal level (neck, thoracic, or low back), pain at the other two levels was also included.

The variables which were selected based on statistical criteria were identified at the analysis phase. All variables were compared across participants with and without pain, using the $\chi^{2}$ or Fisher's exact tests for categorical variables and the Mann-Whitney's U for numerical ones, and all variables showing statistically significant differences between participants with and without each type of pain (NP, TP, LBP, or PASL), were also included in the corresponding regression model.

A non-automatic backward strategy was followed, using the value $p<0.05$ to eliminate variables from the model.

Collinearity in the models was assessed following the criteria proposed by Belsley [48]. In order to assess the accuracy of the final models, both their discrimination and calibration were evaluated. Discrimination was assessed with the area under the ROC curve (AUC), whereas the Hosmer-Lemeshow test was used to assess calibration. An AUC $>0.7$ and a $p>0.05$ in the Hosmer-Lemeshow test suggest acceptable discrimination and calibration, respectively [49].

All analyses were conducted with Stata 14.1 statistical package software (StataCorp. 2015. Stata Statistical Software: Release 14. College Station, TX: StataCorp LP) and SPSS version 15 (SPSS Inc., Chicago, IL, USA) 


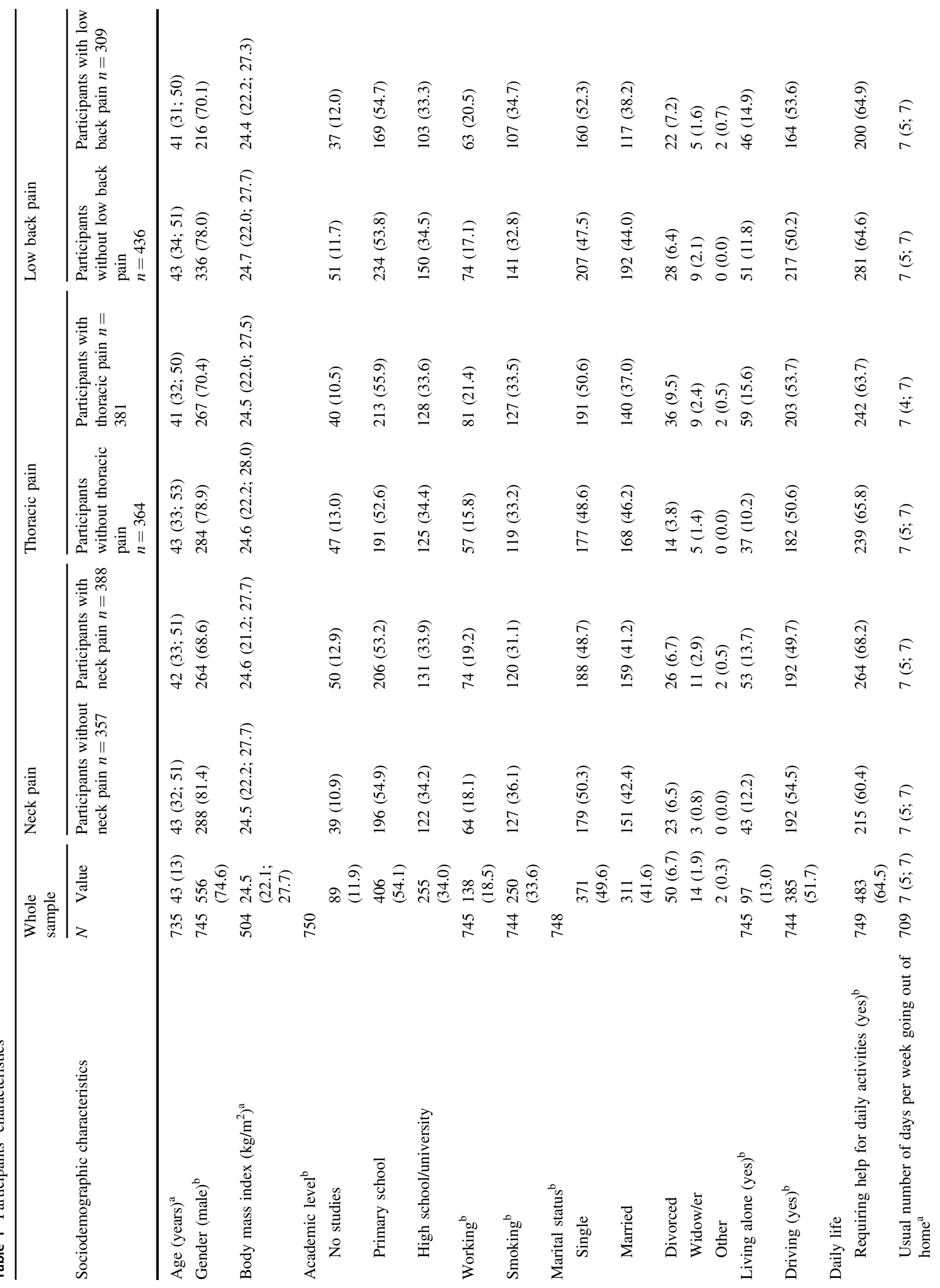




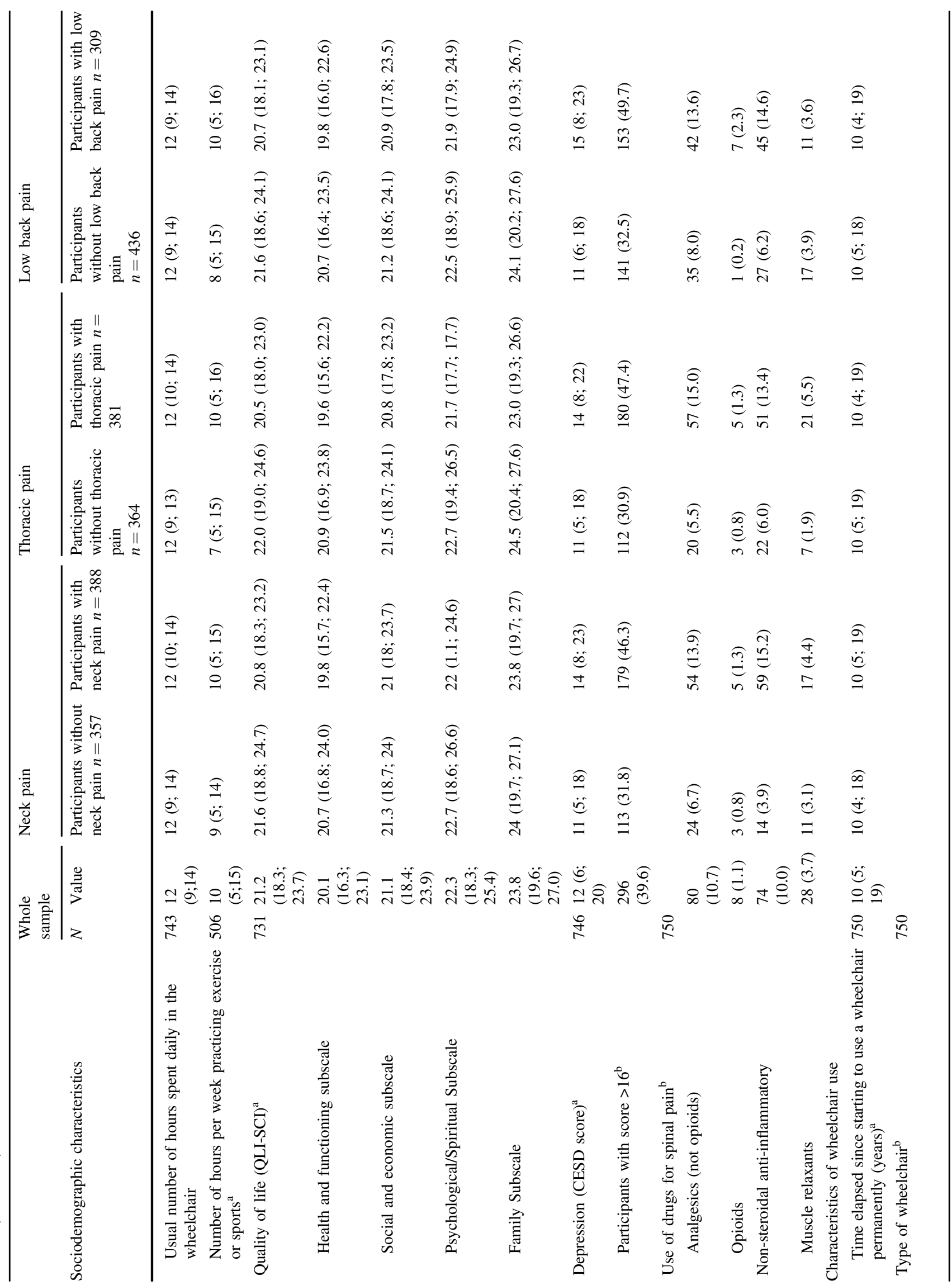




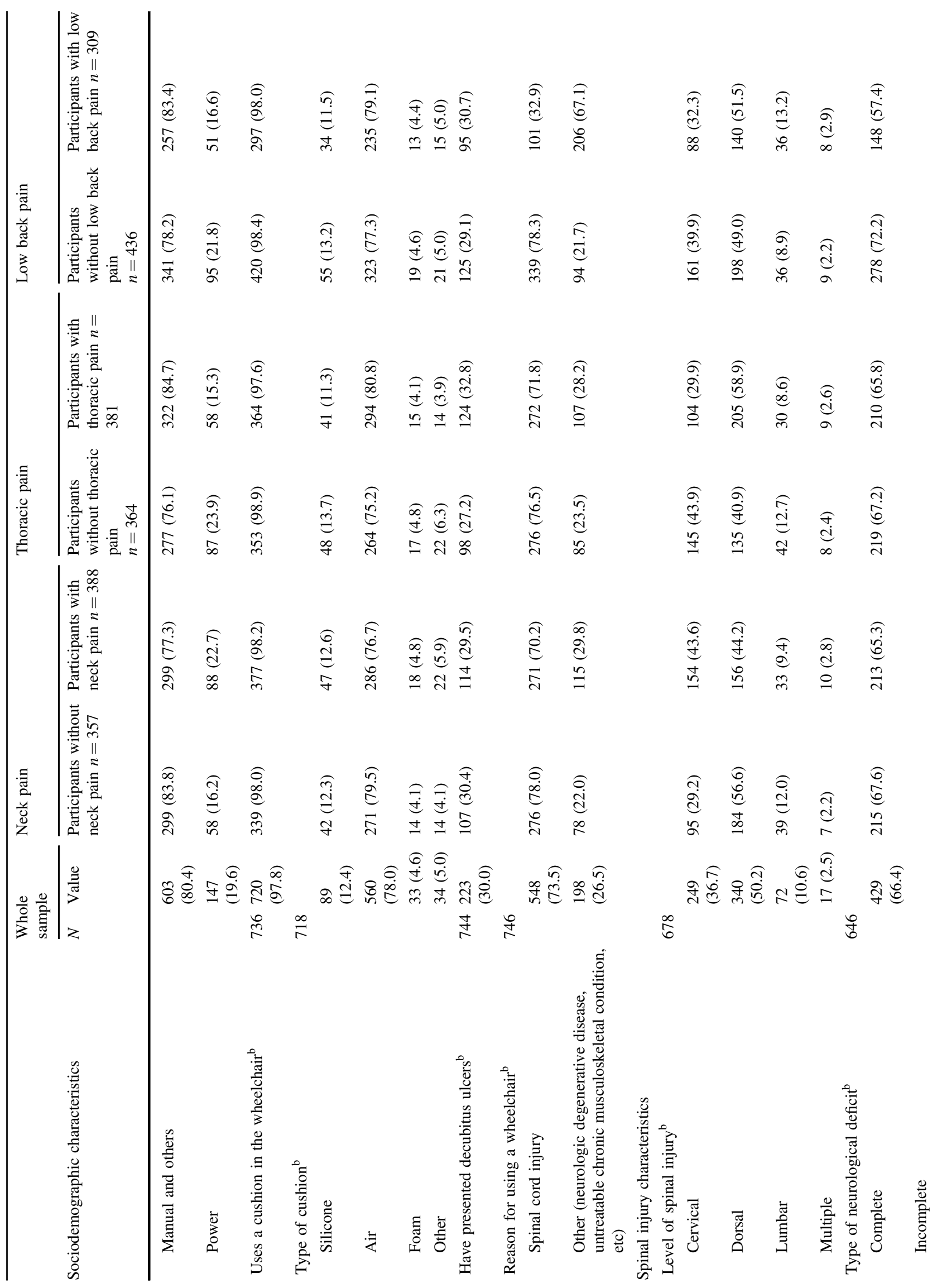




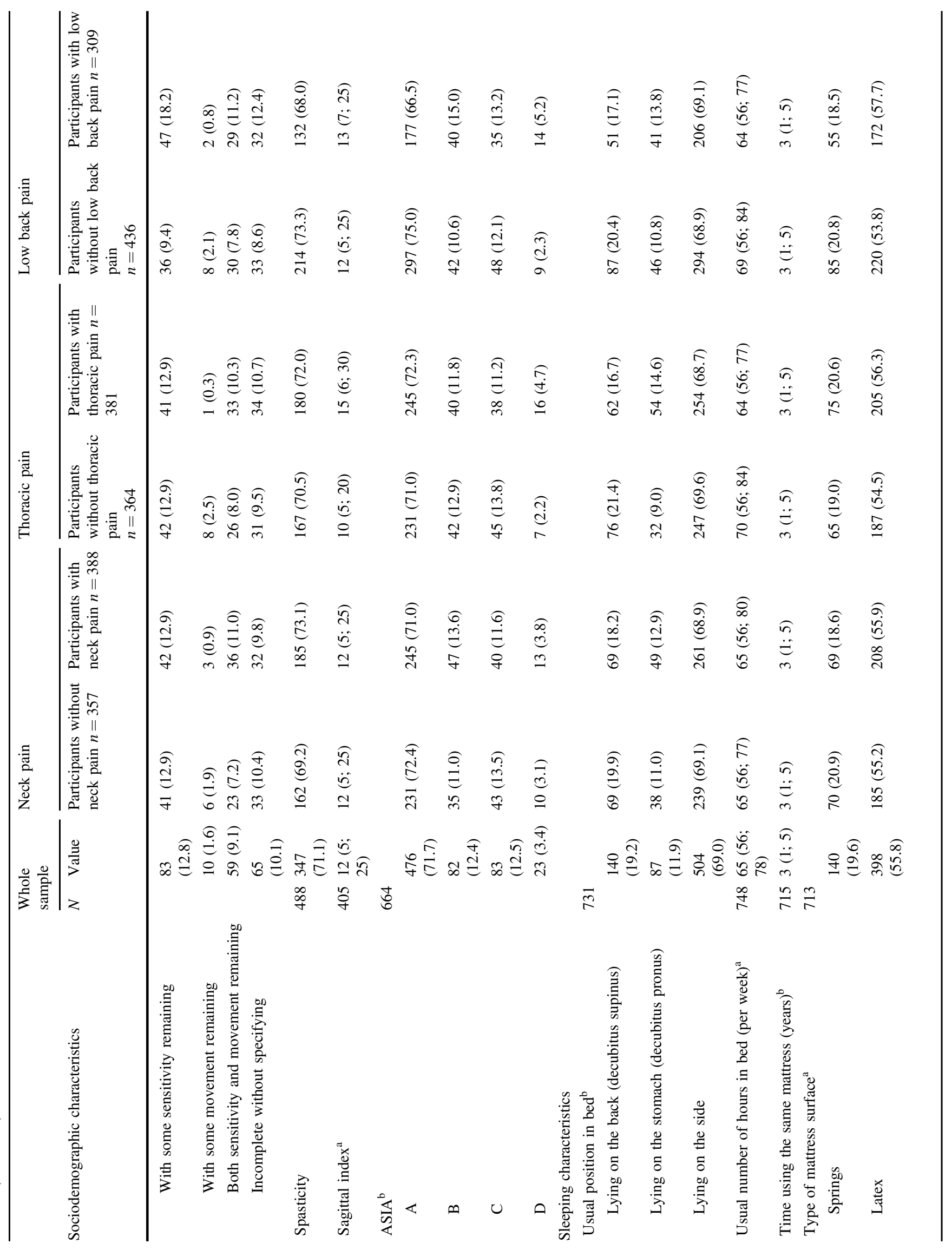




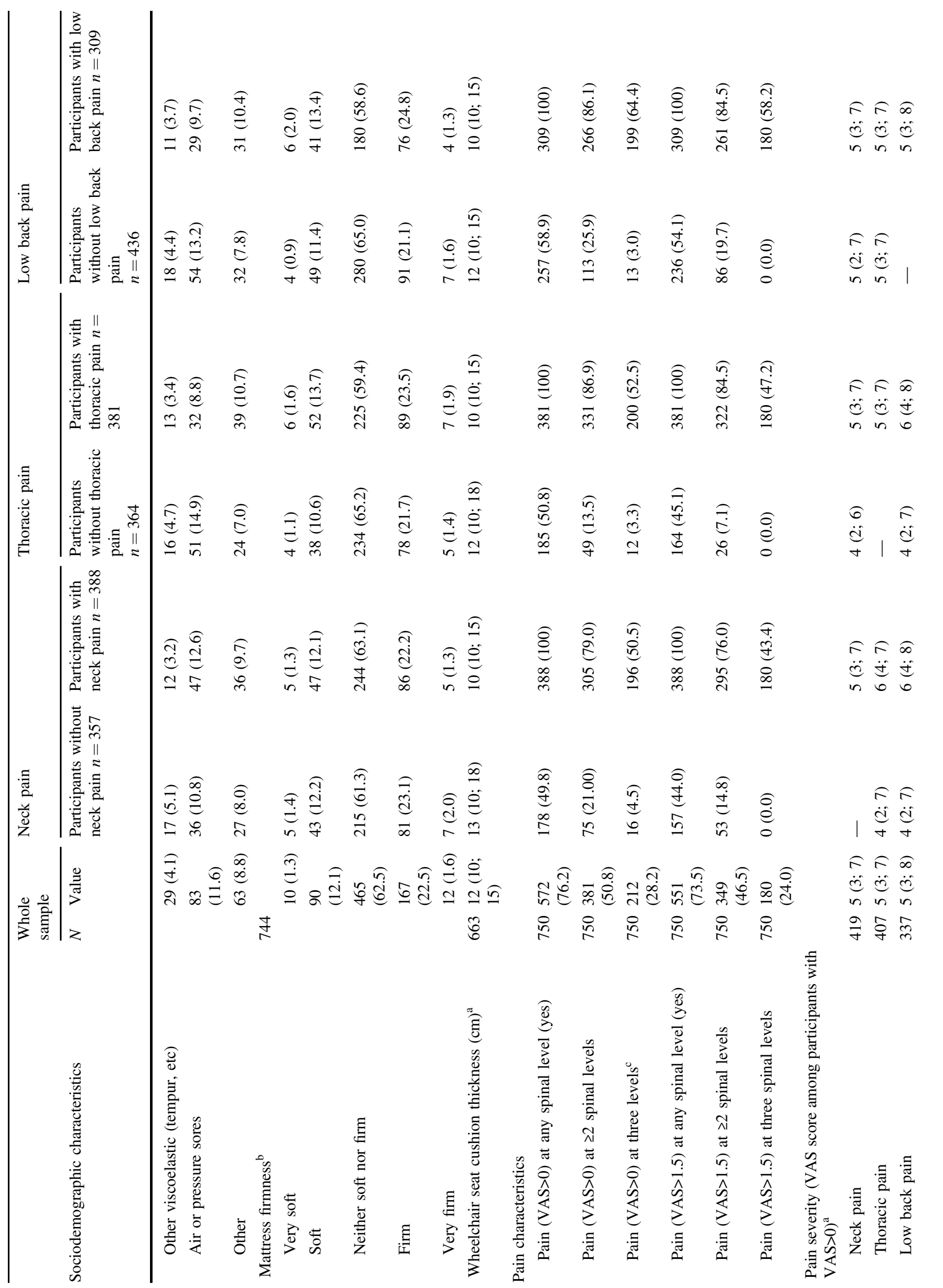




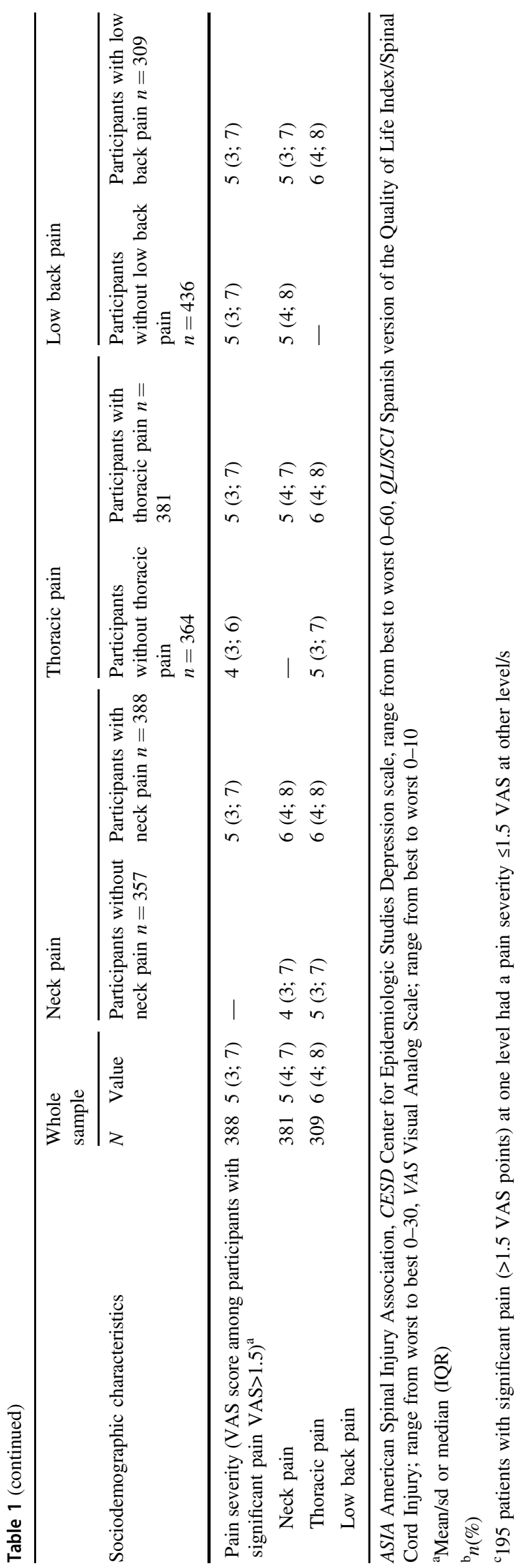

\section{Results}

Sample

Among the 788 persons who were screened, 26 were excluded for being permanent wheelchair users for $<1$ year, and 12 for being unable to distinguish neurophatic from mechanical pain. All the persons invited to participate in the study, accepted. Therefore, 750 were included. Their mean (SD) age was 43 (13) years, median (IQR) duration of time elapsed since starting to permanently use a wheelchair was $10(5 ; 19)$ years, $74 \%$ had suffered a spinal cord injury, $76 \%$ suffered from pain at $\geq 1$ spinal level, $66 \%$ required help for daily activity, and only $19 \%$ were working. Table 1 shows sample characteristics for the whole sample and broken down by participants, which reported and did not report NP, TP, and LBP.

\section{Prevalence of spinal pain}

Point prevalence $(95 \% \mathrm{CI}$ ) for pain of any severity ( $>0$ VAS points) was $56 \%(52.6,59.8)$ for NP, $55 \%(51.0,58.2)$ for TP, $45 \%(41.6,48.9)$ for LBP, and $76 \%(72.9,79.1)$ for pain at any spinal level.

Point prevalence $(95 \% \mathrm{CI}$ ) for pain $\geq 1.5$ VAS points was $52 \%(48.4,55.7)$ for NP, $51 \%(47.5,54.8)$ for $\mathrm{TP}, 42 \%$ $(37.9,45.1)$ for LBP, and $73 \%(70.0,76.4)$ for pain at any spinal level.

\section{Regression models}

All variables showing statistically significant differences across participants with and without pain at each spinal level (NP, TP, LBP, or PASL), were included in the corresponding regression model.

Variables included in the four maximal models were: age, gender, number of hours per week doing exercise or sport, quality of life (QLI-SCI), depression (CESD score), type of wheelchair, reason for using a wheelchair, level of spinal injury, and pain at the other two levels. Additional variables were: (a) in the model on NP: wheelchair seat cushion thickness and requiring help for daily activities, (b) in the model on TP sagittal index, living alone, marital status, usual position in bed, and usual number of hours in the wheelchair and in bed, (c) in the model on LBP: type of neurological deficit, ASIA score, usual number of hours in bed, and number of hours doing exercise or sport per week, (d) in the model on pain at any level: living alone, analgesics, NSAIDs, presence of decubitus ulcers, and type of neurological deficit. There was no collinearity among variables.

Discrimination and calibration of the models were acceptable, with values of the AUC and results from the 


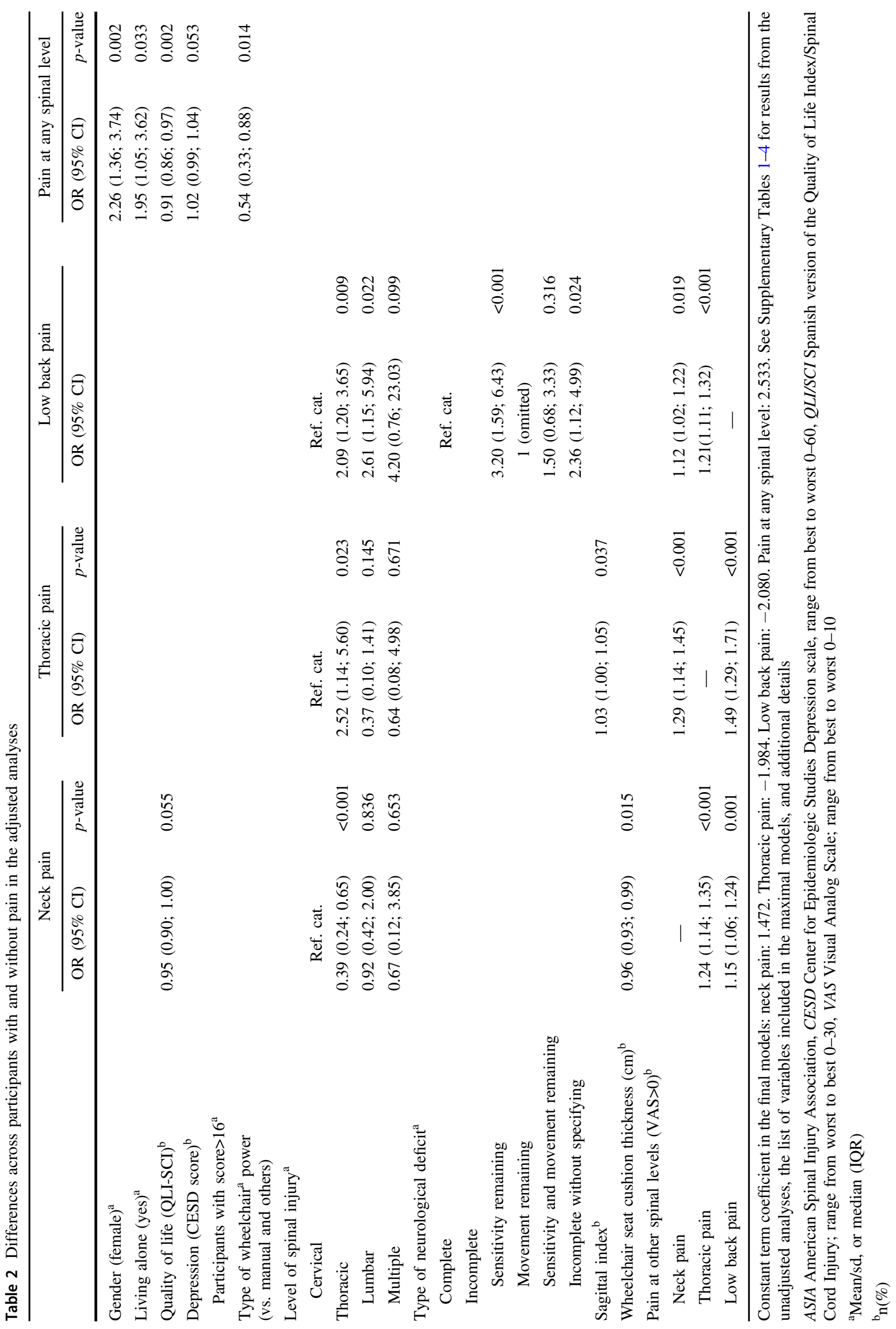


Hosmer-Lemeshow being 0.751 (95\% CI: 0.713, 0.789) and $p=0.638$ for the model on NP, $0.818(0.778,0.859)$ and $p=0.420$ for the model on TP, $0.818(0.778,0.859)$ and $p=0.420$ for the model on LBP, and $0.701(0.660$, 0.743 ) and $p=0.190$ for the model on pain at any level.

\section{Factors associated with a higher prevalence of pain}

As shown in Table 2 and Supplementary Tables 1-4, results showed that pain at any of the three spinal levels (neck, thoracic, or low back areas), was associated with pain at the other two locations.

In addition, factors associated with NP were: spinal injury at the cervical (vs. thoracic) level, and use of thinner wheelchair seat cushions. The association between NP and poorer health-related quality of life was close to statistical significance ( $p=0.055$; Table 2; Supplementary Table 1).

Factors associated with TP were: greater sagittal index and spinal injury at the thoracic level.

Factors associated with LBP were: having had a spinal injury at the thoracic or lumbar levels, and having some sensation remaining (Table 2; Supplementary Table 3).

The association between NP and poorer health-related quality of life, was close to statistical significance $(p=$ 0.055 . Table 2; Supplementary Table 1).

Factors associated with suffering from pain at any spinal level were: being female, living alone, using a non-power wheelchair, and having a worse qualify of life. The association between pain and presenting a higher score for depression was close to statistical significance $(p=0.053$. Table 2; Supplementary Table 4).

\section{Discussion}

In this study, the point prevalence of common spinal pain among wheelchair users was $52 \%$ for NP, $51 \%$ for TP, $41 \%$ for LBP, and $76 \%$ for pain at any spinal level (Table 1). These results are generally consistent with those from previous studies [3-13], including a systematic review, which found a prevalence of $47 \%$ (95\% CI 43;50) for common TP and of $49 \%(44 ; 55)$ for common LBP [8]. It should be noted that this previous review only focused on chronic (not acute) pain among persons using a wheelchair specifically due to a spinal cord injury [8], while the current study focused on all types of common spinal pain and $27 \%$ of participants used a wheelchair for reasons other than spinal cord injury (Table 1).

As in most epidemiologic studies among the walking population, "pain" was defined as any VAS score $>0$ points when calculating its prevalence. However this definition implies that participants with mild, clinically irrelevant backache, who would never seek health care for this reason, are also classified as "back pain sufferers". Therefore, "significant pain" was defined as any pain severity, which can show a clinically significant improvement (i.e., over 1.5 VAS points) [46, 47]. Prevalence using this threshold turned out to be very similar; for instance, prevalence of "pain at any spinal level" was $76 \%$ using the first definition, and $73 \%$ when "pain" was restricted to values $>1.5$ VAS points. Setting the values for "significant" pain at higher values would change this figure. For instance, should the cut-off value for "significant" pain have been established at 3 or 5 VAS points, prevalence would have been $37 \%$ or $28 \%$, respectively.

The prevalence of each of the different types of spinal pain (NP, TP, etc) among permanent wheelchair users found in this study is higher than the prevalence reported for the same type of pain among the general population [1]. This suggests that wheelchair users may be specially susceptible to suffering spinal pain. Moreover, this study shows that, in this population, suffering from spinal pain is associated with a significantly lower quality of life, which is consistent with previous studies $[5,14,16]$. These facts suggest that future research should be undertaken in order to: identify the factors predicting or causing spinal pain in this population, define prevention strategies and methods to reduce its impact, and assess the effectiveness, safety, and efficiency of such strategies and methods.

Most studies focusing on risk factors for neck and back pain among wheelchair users have focused on ergonomic characteristics of the wheelchair [20-31], as opposed to other factors such as those analyzed in this study. This limits comparing their results.

This study analyzed most variables, which have shown to be associated with spinal pain in the general population, and those which the authors expected could play a role in the case of persons who use a wheelchair permanently. However, very few actually showed to have a significant association with pain prevalence (Table 2; Supplementary Tables 1-4). This suggests that identifying factors and mechanisms associated with neck or back pain may be as elusive among wheelchair users, as it has proven to be among the general population. Neck and back pain among permanent wheelchair users might be associated with factors other than those analyzed in this study, such as the relationship between the subjects' physical characteristics and wheelchair size and shape (which, in turn, may condition body position when using the wheelchair), or muscle functionality, physical condition, and training. Future studies should assess these and other factors, which have not been analyzed in the current study.

This was a cross-sectional study and, therefore, clinical sense must be applied to interpret the associations found. For instance, it is more likely that suffering from pain at any spinal level triggers the use of analgesics and NSAIDs, than 
the reverse (i.e., that using these drugs triggers pain) (Supplementary Table 4).

This study assessed association, and association does not mean causation. However, lack of association makes causation very unlikely, and the discrimination and calibration of the regression models were acceptable. Therefore, some associations found in this study may provide a basis for designing preventive strategies, although their effectiveness should be assessed before implementing them in routine practice. Trying to get the sagittal index to be as close to normal as possible, is already a goal when operating on spinal fractures, and results from this study provide yet another reason for supporting this practice. After adjusting for all the other variables, using an power wheelchair was found to be associated with a lower prevalence of pain at any spinal level, and using thicker wheelchair seat cushions was associated with less NP. This suggests that the appropriate longitudinal studies should be conducted to assess whether these are actually effective preventive or therapeutic measures and, if so, ergonomic research should be conducted to refine the design of wheelchairs factoring in these concepts.

Among the general population, avoiding bed rest, active management, and physical activity/exercise are the preventive measures best supported by the available evidence $[33,34]$, and some previous observational studies have found that, among wheelchair users, physical activity is associated with less pain, fatigue, and depression [32]. However, such an association could not be documented in this study, maybe because very few participants practiced exercise or sports (Table 1) or because the biomechanics involved in physical activity and sports participation are different among wheelchair users. Nevertheless, physical activity has shown to be associated with many positive physical and psychological effects beyond spinal pain, so results from this study should not discourage wheelchair users from being as physically active as possible.

It is noteworthy that in the crude analysis, a significant association was found between depression and pain, but it ceased to be significant when adjusting for other factors (Table 2; Supplementary Tables 1-4). This suggests that, although wheelchair users may present spinal pain and depression simultaneously, the two are not directly correlated in this specific population, that is depression is not associated with reporting spinal pain, and pain is not associated with being depressed. However, the $p$-value for the association between depression and PASL was 0.053, which was very close to the cut-off point for statistical significance (0.050), and many studies have found associations between pain and depression in the general population as well as among wheelchair users [5, 17]. These facts suggest that the lack of association between pain and depression in this study may be due to the characteristics of the sample. Most participants in this study were severely impaired; in general, they spent $12 \mathrm{~h}$ per day lying in bed, over $60 \%$ required help for daily activities, $<20 \%$ worked, and $\sim 40 \%$ had a CES-D score over 16 , suggesting depression (Table 1).

Although $>50 \%$ of participants were single, divorced, or widow/ers, $<15 \%$ lived alone, which may reflect the strength of social and family support in the Spanish culture. A previous observational study in Iran found that, among wheelchair users, social support was not associated with pain [5]. However, in this study, living alone was associated with a higher prevalence of spinal pain at any level, suggesting that, in Spain, social support and physical aid for daily living may have a protective effect on spinal pain.

Representativeness of the sample should be discussed. This study focused on common ("mechanical") spinal pain, and this type of pain can concur with neurophatic pain. Therefore, it was necessary to exclude persons who were not able to distinguish between the two types of pain. In Spain, the National Health Service provides health care for free for all residents in the country. This includes education, training, and periodical follow-up consultations at specialized hospitals for all persons who lose the ability to ambulate. Participants in this study were recruited consecutively in such hospitals. None of the screened persons were excluded for reasons other than non compliance with predefined inclusion criteria, and none of those who were invited declined. Therefore, generalizability of findings to permanent wheelchair users across the country does not appear to be a major concern. However, it is possible that a different sample comprising wheelchair users with a more active lifestyle would have led to different results especially on the potential effect of physical activity. Future studies should explore risk factors for spinal pain among specific subsamples of wheelchair users, such as persons who have lost their ability to ambulate due to spinal injury.

Some variables had a few missing data. However, very few had $\geq 5 \%$ missing data, and the only ones with $>15 \%$ were "body mass index" and "number of hours per week doing exercise or practicing sports" (Table 1). This does not appear to challenge the conclusions of this study.

\section{Study limitations}

This study focused on persons who use a wheelchair permanently, and it excluded those who use it transitorily or intermittently. Therefore, results may not apply to the latter. This limitation derives from the study objective, and persons using a wheelchair temporarily (e.g., for fractures or recovery from surgery) represent a different population. 


\section{Conclusions}

In conclusion, this study shows that the prevalence of spinal pain among wheelchair users is high, and that spinal pain is associated with a lower quality of life. Among the variables associated with a higher risk of pain identified in this study, the main modifiable factors are: sagittal index for thoracic fractures, thickness of the wheelchair seat cushion for NP, and use of a power wheelchair for pain at any spinal level. The potential preventive or therapeutic value of the latter two should be assessed by conducting the appropriate longitudinal studies.

Acknowledgements We are grateful to the Hospital Nacional de Parapléjicos (Toledo), Centro de Referencia Estatal para la Atención a Personas con Grave Discapacidad y para la Promoción de la Autonomía Personal y Atención a la Dependencia (San Andrés del Rabanedo, León), and the Centro de Recuperación de Personas con Discapacidad Física (CRMF), from Salamanca and Madrid, for their operational help in recruiting the sample. We are also grateful to the Spanish Back Pain Research Network (SBPRN), a not for profit, Spanish private organization specializing in medical research on neck and back pain, with no links to the health industry, for having funded this study.We are grateful to the Hospital Nacional de Parapléjicos (Toledo), Centro de Referencia Estatal para la Atención a Personas con Grave Discapacidad y para la Promoción de la Autonomía Personal y Atención a la Dependencia (San Andrés del Rabanedo, León), and the Centro de Recuperación de Personas con Discapacidad Física (CRMF), from Salamanca and Madrid, for their operational help in recruiting the sample. We are also grateful to the Spanish Back Pain Research Network (SBPRN), a not for profit, Spanish private organization specializing in medical research on neck and back pain, with no links to the health industry, for having funded this study.

\section{Compliance with ethical standards}

Conflict of interest The authors declare that they have no competing interests.

Disclaimer The funding institution had no role in the design and conduction of the study; data collection; management, analysis and interpretation of the data; preparation, review and approval of the manuscript; or the decision to submit the article for publication.

\section{References}

1. Global Burden of Disease Study 2013 Collaborators. Global, regional, and national incidence, prevalence, and years lived with disability for 301 acute and chronic diseases and injuries in 188 countries, 1990-2013: a systematic analysis for the Global Burden of Disease Study 2013. Lancet. 2015;386:743-800.

2. Dagenais S, Caro J, Haldeman S. A systematic review of low back pain cost of illness studies in the United States and internationally. Spine J. 2008;8:8-20.

3. Samuelsson K, Larsson H, Thyberg M, Gerdle B. Wheelchair seating intervention. Results from a client-centered approach. Disabil Rehabil. 2001;23:677-82.

4. Boninger ML, Cooper RA, Fitzgerald SG, Lin J, Cooper R, Dicianno B, et al. Investigating neck pain in wheelchair users. Am J Phys Med Rehabil. 2003;82:197-202.
5. Khazaeipour Z, Ahmadipour E, Rahimi-Movaghar V, Ahmadipour F, Vaccaro AR, Babakhani B. Association of pain, social support and socioeconomic indicators in patients with spinal cord injury in Iran. Spinal Cord. 2017;55:180-6.

6. Spyridonis F, Ghinea G. A pilot study to examine the relationship of $3 \mathrm{D}$ pain drawings with objective measures in mobility impaired people suffering from low back-pain. Conf Proc IEEE Eng Med Biol Soc. 2010;2010:3895-8.

7. Gibson J, Frank A. Pain experienced by electric-powered chair users: a pilot exploration using pain drawings. Physiother Res Int. 2005;10:110-5.

8. Michailidou C, Marston L, De Souza LH, Sutherland I. A systematic review of the prevalence of musculoskeletal pain, back and low back pain in people with spinal cord injury. Disabil Rehabil. 2014;36:705-15.

9. Müller R, Brinkhof MW, Arnet U, Hinrichs T, Landmann G, Jordan $\mathrm{X}$, et al. Prevalence and associated factors of pain in the Swiss spinal cord injury population. Spinal Cord. 2017;55:346-54.

10. Finnerup NB, Jensen MP, Norrbrink C, Trok K, Johannesen IL, Jensen TS, et al. A prospective study of pain and psychological functioning following traumatic spinal cord injury. Spinal Cord. 2016;54:816-21.

11. Mahnig S, Landmann G, Stockinger L, Opsomer E. Pain assessment according to the International Spinal Cord Injury Pain classification in patients with spinal cord injury referred to a multidisciplinary pain center. Spinal Cord. 2016;54:809-15.

12. Gupta N, Solomon J, Raja K. Pain after paraplegia: a survey in India. Spinal Cord. 2010;48:342-6.

13. Tavares IR, Franzoi AC, Araújo AQ. Low-back pain in HTLV-Iassociated myelopathy/tropical spastic paraparesis: nociceptive or neuropathic? Spinal Cord. 2010;48:134-7.

14. Siddall PJ, McIndoe L, Austin P, Wrigley PJ. The impact of pain on spiritual well-being in people with a spinal cord injury. Spinal Cord. 2017;55:105-11.

15. Cruz-Almeida Y, Alameda G, Widerström-Noga EG. Differentiation between pain-related interference and interference caused by the functional impairments of spinal cord injury. Spinal Cord. 2009;47:390-5.

16. Tran J, Dorstyn DS, Burke AL. Psychosocial aspects of spinal cord injury pain: a meta-analysis. Spinal Cord. 2016;54:640-8.

17. Ataoğlu E, Tiftik T, Kara M, Tunç H, Ersöz M, Akkuş S. Effects of chronic pain on quality of life and depression in patients with spinal cord injury. Spinal Cord. 2013;51:23-6.

18. Kennedy P, Lude P, Taylor N. Quality of life, social participation, appraisals and coping post spinal cord injury: a review of four community samples. Spinal Cord. 2006;44:95-105.

19. Ariens GA, Bongers PM, Douwes M, Miedema M, Hoogendoorn $\mathrm{W}$, van der Wal G, et al. Are neck flexion, neck rotation and sitting at work risk factors for neck pain? Results of a prospective cohort study. Occup Environ Med. 2001;58:200-7

20. Kirby RL, Fahie CL, Smith C, Chester EL, Macleod DA. Neck discomfort of wheelchair users: effect of neck position. Disabil Rehabil. 2004;26:9-15.

21. Samuelsson K, Björk M, Erdugan AM, Hansson AK, Rustner B. The effect of shaped wheelchair cushion and lumbar supports on under-seat pressure, comfort, and pelvic rotation. Disabil Rehabil Assist Technol. 2009;4:329-36.

22. Li CT, Chen YN, Chang CH, Tsai KH. The effects of backward adjustable thoracic support in wheelchair on spinal curvature and back muscle activation for elderly people. PLoS ONE. 2014;9: e113644.

23. Troy BS, Cooper RA, Robertson RN, Grey TL. An analysis of work postures of manual wheelchair users in the office environment. J Rehabil Res Dev. 1997;34:151-61. 
24. DiGiovine CP, Cooper RA, Wolf E, Fitzgerald SG, Boninger ML. Analysis of whole-body vibration during manual wheelchair propulsion: a comparison of seat cushions and back supports for individuals without a disability. Assist Technol. 2003;15:129-44.

25. Nakata M. Labor of freight-container tractor drivers and low back pain: characteristics of the low back pain through clinical findings. Sangyo Igaku. 1987;29:279-91.

26. Magnusson ML, Pope MH, Wilder DG, Areskoug B. Are occupational drivers at an increased risk for developing musculoskeletal disorders? Spine. 1996;21:710-7.

27. Scutter $S$, Turker KS, Hall R. Headaches and neck pain in farmers. Aust J Rural Health. 1997;5:2-5.

28. Johanning E. Back disorders and health problems among subway train operators exposed to whole body vibration. Scand J Work Environ Health. 1991;17:414-9.

29. Cooper RA, Wolf E, Fitzgerald SG, Kellerher A, Ammer W, Boninger ML, et al. Evaluation of selected sidewalk pavement surfaces for vibration experienced by users of manual and powered wheelchairs. J Spinal Cord Med. 2004;27:468-75.

30. Viikari-Juntura E, Martikainen R, Luukonnen R, Mutanen P, Takala EP, Riihimäki H. Longitudinal study on work related and individual risk factors affecting radiating neck pain. Occup Environ Med. 2001;58:345-52.

31. Wilder D, Magnusson ML, Fenwick J, Pope M. The effect of posture and seat suspension design on discomfort and back muscle fatigue during simulated truck driving. Appl Ergonomics. 1994;24:66-76.

32. Tawashy AE, Eng JJ, Lin KH, Tang PF, Hung C. Physical activity is related to lower levels of pain, fatigue and depression in individuals with spinal-cord injury: a correlational study. Spinal Cord. 2009;47:301-6.

33. Dahm KT, Brurberg KG, Jamtvedt G, Hagen KB. Advice to rest in bed versus advice to stay active for acute low-back pain and sciatica. Cochrane Database Syst Rev. 2010;6:CD007612.

34. Geneen LJ, Moore RA, Clarke C, Martin D, Colvin LA, Smith BH. Physical activity and exercise for chronic pain in adults: an overview of Cochrane Reviews. Cochrane Database Syst Rev. 2017;4:CD011279.

35. De Waard F. Body Mass Index. J Chronic Dis. 1978;31:129.

36. Matsuura P, Waters RL, Adkins RH, Rothman S, Gurbani N, Sie I. Comparison of computerized tomography parameters of the cervical spine in normal control subjects and spinal cord-injured patients. J Bone Joint Surg Am. 1989;71:183-8.
37. Waters RL, Adkins R, Yakura J, Vigil D. Prediction of ambulatory performance based on motor scores derived from standards of the American Spinal Injury Association. Arch Phys Med Rehabil. 1994;75:756-60.

38. El Masry WS, Tsubo M, Katoh S, El Miligui YH, Khan A. Validation of the American Spinal Injury Association (ASIA) motor score and the National Acute Spinal Cord Injury Study (NASCIS) motor score. Spine. 1996;21:614-9.

39. Huskinson EC. Measurement of pain. Lancet. 1974;2:1127-31.

40. Kovacs FM, Seco, Royuela A, Barriga B, Zamora J. The assessment of daily physical activity among persons using a wheelchair permanently. Development and assessment of the ActiWC questionnaire. Disabil Rehabil. (submitted).

41. Radloff LS. The CES-D scale: a self-report depression scale for research in the general population. Appl Psychol Meas. 1977;1:385-401.

42. May LA, Warren S. Measuring quality of life of persons with spinal cord injury: external and structural validity. Spinal Cord. 2002;40:341-50.

43. May LA, Warren S. Measuring quality of life of persons with spinal cord injury: substantive and structural validation. Qual Life Res. 2001;10:503-15.

44. Kovacs FM, Barriga A, Royuela A, Seco J, Zamora J, Spanish adaptation of the Quality of Life index-Spinal Cord Injury Version. Spinal Cord. 2016;54:895-900

45. Harrell FE Jr, Lee KL, Califf RM, Pryor DB, Rosati RA. Regression modelling strategies for improved prognostic prediction. Stat Med. 1984; 3:143-52.

46. Kovacs FM, Abraira V, Royuela A, Corcoll J, Alegre L, Cano A, et al. Minimal clinically important change for pain intensity and disability in patients with nonspecific low back pain. Spine. 2007;32:2915-20.

47. Kovacs FM, Abraira V, Royuela A, Corcoll J, Alegre L, Tomás $\mathrm{M}$, et al. Minimum detectable and minimal clinically important changes for pain in patients with nonspecific neck pain. BMC Musculoskelet Disord. 2008;9:43. 10.1186/1471-2474-9-43

48. Belsley D, Kuh E, Welsch R. Regression diagnostics. New Jersey: Wiley; 1980.

49. Harrell FE. Regression modeling strategies with applications to linear models, logistic regression, and survival analysis. New York: Springer series in statistics; 2001.

\section{Affiliations}

\section{Francisco M. Kovacs $\mathbb{D}^{1,2} \cdot$ Jesús Seco ${ }^{2,3} \cdot$ Ana Royuela ${ }^{2,4} \cdot$ Andrés Barriga $^{2,5} \cdot$ Javier Zamora ${ }^{2,6,7,8}$}

1 Unidad de la Espalda Kovacs, Hospital Universitario HLAMoncloa. 81, Avda. Valladolid, 28008 Madrid, Spain

2 Spanish Back Pain Research Network, Madrid, Spain

3 Institute of Biomedicine (IBIOMED), University of León, University of the Basque Country, Campus Universitario, 24071 León, Spain

4 Clinical Biostatistics Unit, Puerta de Hierro University Hospital, Instituto de Investigación Puerta de Hierro (IDIPHIM), Madrid, Spain
5 Orthopedic Surgery Department, National Hospital for Paraplegics, University Castilla-La Mancha, Finca La Peraleda s/n, 45071 Toledo, Spain

6 Unidad de Bioestadística Clínica, Hospital Ramón y Cajal, IRYCIS, Ctra. Colmenar Km 9.1, 28034 Madrid, Spain

7 Barts and The London School of Medicine and Dentistry, Queen Mary University of London, London, UK

8 CIBER Epidemiology and Public Health (CIBERESP), Madrid, Spain 